\title{
Effects on symptoms and lung function in humans experimentally exposed to diesel exhaust
}

\author{
B Rudell, M-C Ledin, U Hammarström, N Stjernberg, B Lundbäck, T Sandström
}

\begin{abstract}
Objectives-Diesel exhaust is a common air pollutant made up of several gases, hydrocarbons, and particles. An experimental study was carried out which was designed to evaluate if a particle trap on the tail pipe of an idling diesel engine would reduce effects on symptoms and lung function caused by the diesel exhaust, compared with exposure to unfiltered exhaust.

Methods-Twelve healthy non-smoking volunteers (aged 20-37) were investigated in an exposure chamber for one hour during light work on a bicycle ergometer at 75 W. Each subject underwent three separate double blind exposures in a randomised sequence: to air and to diesel exhaust with the particle trap at the tail pipe and to unfiltered diesel exhaust. Symptoms were recorded according to the Borg scale before, every 10 minutes during, and 30 minutes after the exposure. Lung function was measured with a computerised whole body plethysmograph.
\end{abstract}

Results-The ceramic wall flow particle trap reduced the number of particles by $46 \%$, whereas other compounds were relatively constant. It was shown that the most prominent symptoms during exposure to diesel exhaust were irritation of the eyes and nose and an unpleasant smell increasing during exposure. Both airway resistance $\left(R_{\mathrm{aw}}\right)$ and specific airway resistance $\left(S R_{\text {aw }}\right)$ increased significantly during the exposures to diesel exhaust. Despite the $46 \%$ reduction in particle numbers by the trap effects on symptoms and lung function were not significantly attenuated.

Conclusion-Exposure to diesel exhaust caused symptoms and bronchoconstriction which were not significantly reduced by a particle trap.

(Occup Environ Med 1996;53:658-662)

Keywords: diesel exhaust; particle trap; air pollution; bronchoconstriction

Diesel exhaust has been shown to cause unwanted biological effects in exposed humans. Workers exposed to diesel exhaust have been reported to have an increased prevalence of such symptoms as burning eyes, headache, nausea, difficult or laboured breathing, cough, pleghm, and wheeze. ${ }^{13}$ Workers exposed to petrol and diesel exhaust have an increased air- way resistance, increased closing volume (CV), and reversible reductions of forced expiratory volume in 1 second $\left(\mathrm{FEV}_{1}\right)$ and forced vital capacity (FVC)..$^{4-7}$

At workplaces where workers have been exposed to diesel exhaust, nitrogen dioxide $\left(\mathrm{NO}_{2}\right)$ has often been measured as an indicator of exposure. Miners, for example, have been found to be exposed to diesel exhaust up to an average concentration of $3.3 \mathrm{ppm} \mathrm{NO} \mathrm{N}_{2}$ during a full workshift, ${ }^{8}$ workers on roll on roll off ships have been exposed to an average concentration of $1.15 \mathrm{ppm} \mathrm{NO}_{2}$ during a whole workshift, ${ }^{5}$ and drivers in a tunnel to an average concentration of $1.3 \mathrm{ppm} \mathrm{NO}{ }_{2}{ }^{7}$ Short term exposures of up to $8 \mathrm{ppm}$ in miners have been reported. ${ }^{9}$

Apart from $\mathrm{NO}_{2}$, diesel exhaust consists of a large variety of gases and vapours. Water and carbon dioxide $\left(\mathrm{CO}_{2}\right)$ are the end products of optimal combustion. Due to incomplete combustion liquid and solid particles and gases are generated. The main gases are carbon monoxide (CO), nitrogen monoxide (NO), and $\mathrm{NO}_{2}$. A small but important percentage of the fuel is polymerised, pyrolysed, cracked, oxidised, sulphonated, and nitrated into several hundred compounds. ${ }^{10-12}$ The structure and concentration of these compounds can be very different depending on the age and size of the engine, the driving modes, fuel, air to fuel mass ratio, fuel additives, motor oil, and engine and outdoor temperature, as well as control devices - for example, particle traps and catalysts. ${ }^{13-16}$ Gases and hydrocarbons are adsorbed or condensed on a carbonaceous core where $5 \%-50 \%$ of the mass of particles can be extractable organic compounds. ${ }^{17}$

In our clinical experience it is common for workers to complain of symptoms related to exposure to diesel exhaust from idling vehicles. Recently we have presented an experimental design including a shunt dilutor for diesel exhaust and an exposure chamber. ${ }^{18}$ To study symptoms people were exposed to controlled diluted diesel exhaust from an idling lorry.

The aim of the study was to evaluate effects on symptoms and lung function caused by exposure to diesel exhaust compared with air, and to evaluate if a particle trap at the tail pipe of the idling diesel engine would abolish or diminish the effects of exhaust.

\section{Subjects and methods}

DESIGN OF THE STUDY

Twelve healthy non-smoking and non-asthmatic subjects, four women and eight men (aged 20-37), were exposed to diluted diesel 


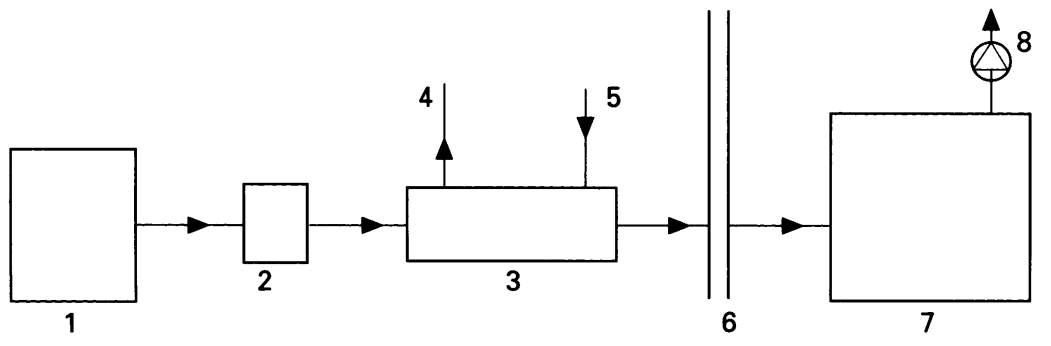

A

B

Figure 1 Schematic view of the experimental setup. A outdoors; $B$ indoors; 1 idling lorry; 2 particle trap; 3 shunt dilutor; 4 shunt tube; 5 air diluter; 6 wall; 7 exposure chamber $(3 \times 3 \times 2 \cdot 3 \mathrm{~m}) ; 8$ air evacuation fan.

exhaust from a continuously idling vehicle in an exposure chamber for one hour.

They were exposed on three separate occasions: to air, to diesel exhaust with a particle trap at the tail pipe, and to unfiltered diesel exhaust. The sequence of exhaust exposure was randomised. The actual exposure was blinded to the subjects and technicians measuring symptoms and lung function. During exposure they performed light work by riding an ergometer bicycle at $75 \mathrm{~W}$. Rest and work on the ergometer bicycle were alternated every 10 minutes. Subjective symptoms were recorded before, every 10 minutes during the exposure, and 30 minutes afterwards. Lung function was measured before and after exposure. The subjects were recruited from an advertisement in the local newspaper and at the University. All participants gave their informed consent and the study was approved by the local ethics committee.

\section{EXPOSURE SETUP}

A continuously idling lorry was parked outside. Most of the exhaust was shunted away before it was diluted by air and fed into the exposure chamber previously shown in detail (fig 1)..$^{18}$

\section{EXPOSURE WITH THE PARTICLE TRAP}

Figure 2 shows the device between the tail pipe and the shunt dilutor. The smaller end (diameter $65 \mathrm{~mm}$ ) of the conical cylinder (length $380 \mathrm{~mm}$ ) was fixed to the tail pipe. The larger end (diameter $140 \mathrm{~mm}$ ) was connected to the cylindrical trap (length $200 \mathrm{~mm}$, diameter 140 $\mathrm{mm})$. An identical conical cylinder was inserted at the other end of the trap. This was connected to the shunt dilutor through a flexible tube (length $800 \mathrm{~mm}$, diameter $100 \mathrm{~mm}$ ).

The tubes, cylinders, and the outer shell of

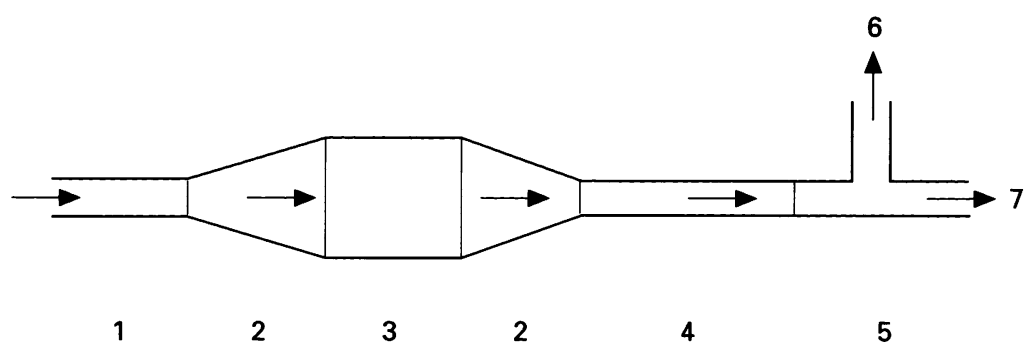

Figure 2 Schematic view of tail pipe, particle trap, and shunt dilutor. 1 tail pipe; 2 conical cylinders; 3 particle trap; 4 flexible tube; 5 shunt dilutor; 6 shunt tube; 7 to air dilution and exposure chamber. the trap were metal and their outer surfaces were heated to about $200^{\circ} \mathrm{C}$ to avoid condensation and changes in the exhaust composition. The size and the shape of the particles have previously been shown not to change in the metallic tube, shunt dilutor, and the tube to the exposure chamber. ${ }^{18}$

\section{EXPOSURE WITHOUT THE PARTICLE TRAP}

The same device was used as for exposure with the trap except that the conical cylinders were connected to each other without the trap between them.

\section{EXPOSURE TO AIR}

The subjects were exposed to pure air through the exposure system. A new tube from the shunt dilutor to the exposure chamber was used to avoid smell from old diesel exhaust. Due to the sound from the evacuation fan in the exposure chamber it was impossible for the subjects to hear whether the engine was running or not.

\section{CHALLENGE TESTS}

After the warming up period, with or without the particulate trap, the exhaust was fed into the exposure chamber. The air in the exposure chamber was changed every 2.3 minutes and the steady state in the exposure chamber was achieved within 10 minutes.

The composition of the diesel exhaust measured as particles, $\mathrm{NO}_{2}, \mathrm{NO}, \mathrm{CO}$, total hydrocarbons, and formaldehyde in the exposure chamber have been shown to be almost constant throughout the three hours. ${ }^{18}$

\section{PARTICLE TRAP}

Figure 3 shows a schematic diagram of the exhaust particle trap, Corning Ex-54 (Corning, New York, USA). The trap has a porous ceramic wall flow filter and honeycomb struc-
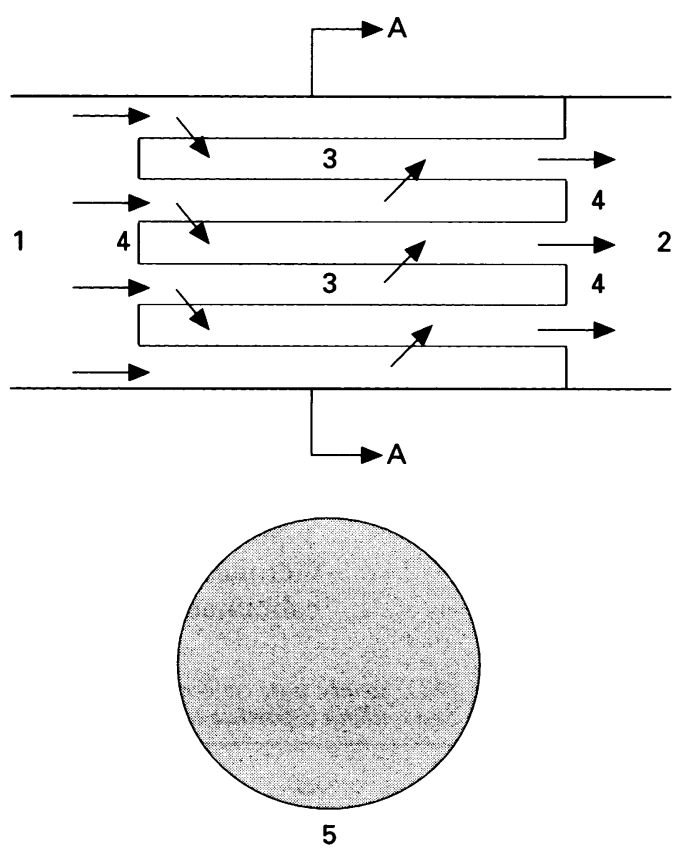

Figure 3 Schematic diagram of the ceramic wall flow particle trap used. 1 exhaust inlet; 2 exhaust outlet; 3 porous ceramic cell walls; 4 ceramic plugs; 5 side view of the trap through plane $A$. 
ture which is housed in a metal shell. Every second channel was open and the others were plugged with ceramic material at the inlet of the exhaust filter. The outlet of the filter was opposite to the inlet. Gases had to pass the ceramic wall before they could leave the filter through the open channels at the outlet of the filter. The Corning Ex-54 had a mean pore size of $22 \mu \mathrm{m}$ and $50 \%$ total porosity. The area of each channel in the trap was $1.9 \times 1.9 \mathrm{~mm}$ and the thickness of the wall between two channels was $0.64 \mathrm{~mm}$.

Two identical traps were used for the tests. The mechanical filter (ceramic walls) in the trap accumulated particles with time. To avoid an excessive pressure drop in the trap the filter was regenerated after four hours of idling, at Volvo in Gothenburg.

VEHICLE, MOTOR OIL, FUEL

The lorry used for the tests was a new Volvo TD1F Intercooler, a six cylinder four stroke, direct injection turbo charged diesel engine, model 1990. At the time of the challenge tests the lorry had been driven $4500 \mathrm{~km}$. It was idling out of doors at $900 \mathrm{rpm}$ during the exposures. Vehicle data were displacement $5.48 \mathrm{dm}^{3}$, bore $98.43 \mathrm{~mm}$, stroke $120 \mathrm{~mm}$, compression ratio $16: 1$, economy speed range $1500-2400 \mathrm{rpm}$, output $2800 \mathrm{rpm}$, net ISO/SAE $152 \mathrm{~kW}$, torque $1600 \mathrm{rpm}$, net ISO/SAE $620 \mathrm{Nm}$. Smoke requirements conformed with European Union regulations, United States Federal register, and the Swedish norms. Mobil, Delvac 1400S, 15-40 W motor oil: and a low sulphur fuel, OK Promil 1 were used (OK Petroleum, Stockholm, Sweden). Major characteristics were $5 \mathrm{ppm}$ sulphur, $4 \%$ by volume aromatics, $<0.5 \%$ by volume olefins, $<0.02 \%$ by volume polycyclic aromatic hydrocarbons (PAHs), centane number 55, nitrogen $1 \mathrm{ppm}$; and start boiling point, end boiling point, and $95 \%$ boiling point were 215 , 295 , and $280^{\circ} \mathrm{C}$ respectively.

\section{EXHAUST ANALYSIS}

The concentrations of particles (number $/ \mathrm{cm}^{3}$ ), $\mathrm{NO}_{2}, \mathrm{NO}, \mathrm{CO}$, and total hydrocarbons were continuously recorded in the exposure chamber as previously described. ${ }^{18} \mathrm{~A}$ Miran 1-A, an IR instrument (Foxboro Co, East Bridgewater, MA, USA), was used for analysis of $\mathrm{CO}$. A chemiluminiscence oxides of nitrogen analyser instrument model 1600 (Columbia Scientific Industries Corp, Austin, TX, USA) analysed $\mathrm{NO}$ and $\mathrm{NO}_{2}$. The total hydrocarbons were analysed with an FID instrument, model 3-300 (JUM Engineering $\mathrm{GmbH}$, Munich, Germany) with a heated prefilter $\left(180^{\circ} \mathrm{C}\right)$ and calibrated with propane. Continuous registra-

Values are median (SD) steady state concentrations during exposure to air and diluted diesel exhaust with and without a particle trap

\begin{tabular}{lllllll}
\hline & $\begin{array}{l}\text { Particles } \\
\times 10^{\circ} \mathrm{cm}^{3}\end{array}$ & $\begin{array}{l}\text { NO: } \\
(\mathrm{ppm})\end{array}$ & NO (ppm) & CO (ppm) & $\begin{array}{l}\text { Total hydro- } \\
\text { carbons } \\
(\mathrm{ppm})\end{array}$ & $\begin{array}{l}\text { Formalde- } \\
\text { hyde } \\
\left(\mathrm{mg} / \mathrm{m}^{3}\right)\end{array}$ \\
\hline $\begin{array}{l}\text { Air } \\
\begin{array}{l}\text { Exhaust without } \\
\text { particle trap }\end{array}\end{array}$ & $<0.01$ & $<0.02$ & $<0.02$ & $<2$ & $<1$ & $<0.005$ \\
$\begin{array}{l}\text { Exhaust with } \\
\text { particle trap }\end{array}$ & $1.4(0.1)$ & $1.9(0.1)$ & $2.7(0.6)$ & $27(4)$ & $4.5(0.3)$ & $0.4(0.06)$ \\
\hline
\end{tabular}

tion of the number of particles $/ \mathrm{cm}^{3}$ was obtained with a condensation particle counter (laser), model 3022 (TSI, St Paul, MN, USA. $\mathrm{X}$-y recorders were used. Formaldehyde was collected on glass fibre filters (diameter $13 \mathrm{~mm}$ ) impregnated with 2,4-dinitrophenylhydrazine ${ }^{19}$ and analysed with high performance liquid chromatography (HPLC), model WISP 712 (Millipore, Milford, MA, USA). Particles were collected in the exposure chamber on Nucleopore filters (porous diameter $0.4 \mu \mathrm{m}$, filter diameter $25 \mathrm{~mm}$ ) with and without the particle trap and analysed with scanning electron microscopy as previously described. ${ }^{18}$ The largest particles $(>0.4 \mu \mathrm{m})$ were calculated visually on scanning electron microscopy photos $(12.5 \times 6.4 \mu \mathrm{m})$.

\section{SYMPTOMS}

The symptoms were registered as previously presented. ${ }^{18}$ Before exposure, every 10 minutes during one hour of exposure, and 30 minutes after exposure the subjects were interviewed by a technician who registered the subjective symptoms according to the questionnaire. The symptoms were: headache, dizziness, nausea, tiredness, tightness of the chest, coughing, difficulty breathing, eye irritation, nose irritation, an unpleasant smell, throat irritation, and a bad taste in the mouth. The symptoms were scored from no symptoms (ranked 0 ) to maximal symptoms (ranked 11) according to the Borg scale. $^{20}$

\section{LUNG FUNCTION}

Before and after each exposure to air and diluted diesel exhaust with and without the particle trap $\mathrm{FEV}_{1}, \mathrm{FVC}$, forced expiratory flow rate at $50 \%$ of FVC $\left(\mathrm{FEF}_{50}\right)$, forced expiratory flow rate between $25-75 \%$ of FVC $\left(\mathrm{FEF}_{25-75}\right)$, airway resistance $\left(R_{\mathrm{aw}}\right)$, specific airway resistance $\left(\mathrm{SR}_{\mathrm{aw}}\right)$, and VTG (volume of trapped gas) were estimated with a whole body plethysmograph (system 2800, Sensor Medics, CA, USA).

\section{STATISTICS}

Wilcoxon's rank sum test for paired observations were used for comparison between exposures. A $P$ value $<0.05$ was considered significant.

\section{Results}

\section{EXPOSURE CHARACTERISTICS}

The table shows the median steady state concentrations of particles, $\mathrm{NO}_{2}, \mathrm{NO}, \mathrm{CO}$, total hydrocarbons, and formaldehyde during exposure to air and diluted diesel exhaust with and without a particle trap. The concentrations of the measured substances were very low during air exposure. With the particle trap the median steady state number of particles decreased to $54 \%$ of the value of unfiltered diesel exhaust while $\mathrm{NO}_{2}, \mathrm{NO}, \mathrm{CO}$, total hydrocarbons, and formaldehyde were relatively unaffected. Scanning electron microscopy showed that particles $\geqslant 0.4 \mu \mathrm{m}$ were reduced by an average $25 \%$ with the particle trap, compared with unfiltered exhaust, as larger particles constitute 

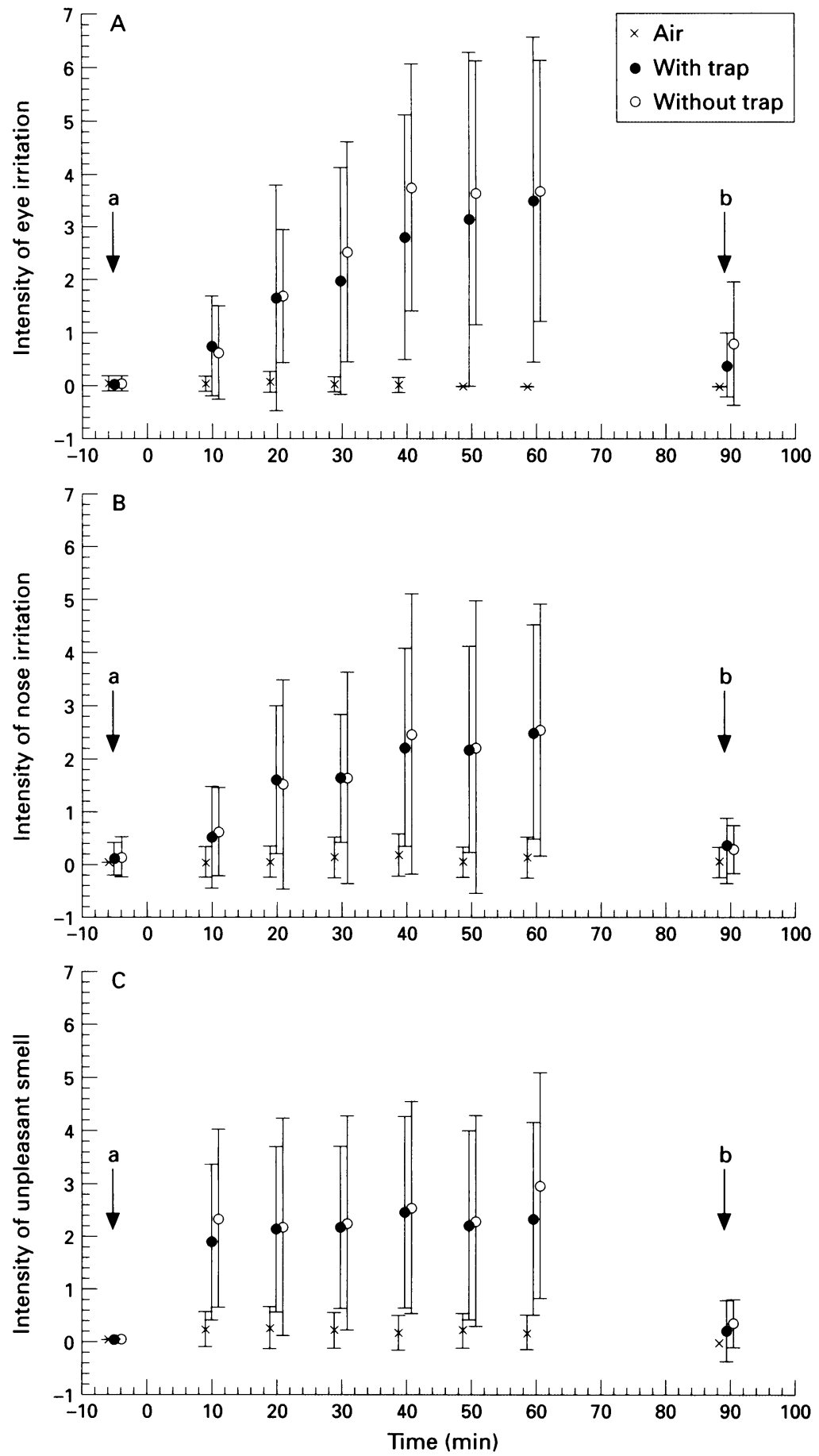

Figure 4 The intensity of the most prominent symptoms, $(A)$ eye, $(B)$ nose irritation, and $(C)$ unpleasant smell according to Borg scale 5 minutes before (arrow a), during, and 30 minutes after exposure (arrow b). The intensities were significantly higher during exposure to diesel exhaust than exposures to air (see results). No significant differences were found with and without the particle trap. The intensity scores are mean (SEM).

only a small proportion of the total number of particles but a large proportion of the mass. This indicates that the mass of exhaust particles was probably reduced, but this was not evaluated further.

SYMPTOMS

Air exposure caused no significant increase in symptoms. The most frequent symptoms during diesel exhaust exposure with and without the particle trap were eye and nose irritation and unpleasant smell. Figure 4 shows the intensity of these symptoms as a function of time during exposure to air, and diesel exhaust with

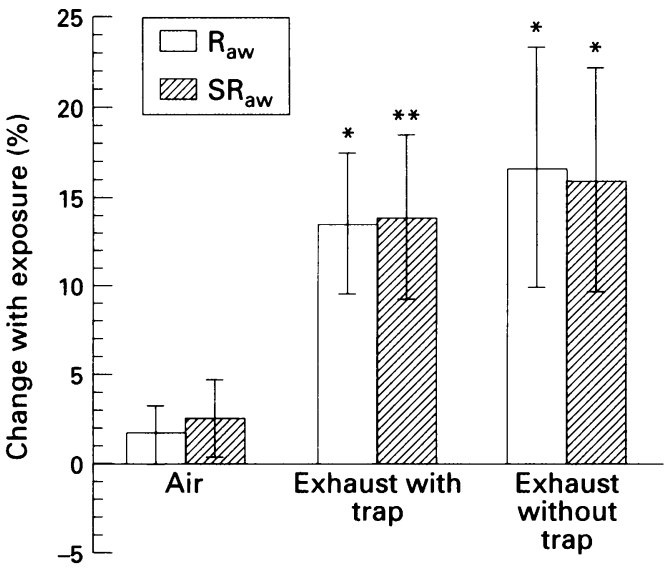

Figure 5 Change (\%) in $R_{a w}$ and $S R_{a w}$ during exposure to air, and diesel exhaust with and without the particle trap. The values are mean (SEM). ${ }^{\star} P<0.05 ;{ }^{\star}{ }^{*} P<$ 0.01 versus exposure to air.

and without a particle trap.

Compared with exposure to air, exposure to diesel exhaust both with and without a trap caused significantly higher symptoms from eyes and nose and unpleasant smell, from 10-60 minutes, $(P<0.01-0.001)$.

Exceptions were for exhaust with a trap versus air, nose irritation at 10 minutes $(P=0.07)$, and eye irritation at 10 minutes $(P<0.05)$.

Thirty minutes after the end of exposure the intensity of the symptoms was negligible. There were no significant differences in symptoms with and without the trap.

\section{LUNG FUNCTION}

Figure 5 shows the change (\%) of $R_{a w}$ and $S R_{a w}$ with exposures. No significant change in $R_{a w}$ and $S_{\mathrm{aw}}$ resulted after exposure to air. Exposure to diluted diesel exhaust with the particle trap showed a significant increase in $R_{a w}$ $(P<0.02)$ and $S_{a w}(P<0.01)$. Exposure to diesel exhaust without the particle trap also caused a significant increase in $R_{a w}(P<0.04)$ and $S_{\mathrm{aw}}(\mathrm{P}<0.03)$. No significant difference of $R_{\mathrm{aw}}$ and $\mathrm{Sr}_{\mathrm{aw}}$ was found between the presence and absence of the particle trap.

The $\mathrm{FEV}_{1}, \mathrm{FVC} \mathrm{FEF}_{50}, \mathrm{FEF}_{25-75}$, and VTG showed non-significant changes during exposure to diesel exhaust with and without the particle trap. Air exposure gave no significant changes in any lung function variables.

\section{Discussion}

In an earlier study of exposure to diesel exhaust ${ }^{18}$ we investigated changes in lung function with dynamic spirometry and found no effect on $\mathrm{FEV}_{1}$ and FVC. In this study, we used more sensitive equipment, a state of the art computerised whole body plethysmograph, and found significantly increased $R_{a w}$ and $S R_{a w}$ both with and without the particle trap compared with exposure to air. Consequently a $46 \%$ reduction of the median steady state particle number was not sufficient to protect against the bronchoconstriction found to be induced by diesel exhaust.

The intensity of the most prominent symptoms in this study, as well as in our former 
study, ${ }^{18}$ were eye and nose irritation and unpleasant smell. These symptoms increased during exposure to exhaust with and without the particle trap. The trap did not protect against the increases found in $R_{a w}$ and $S R_{a w}$. In the earlier study the intensity of unpleasant smell was higher and nose irritation was less pronounced. ${ }^{18}$ One explanation could be the lower sulphur and higher paraffin and naphthene content in the fuel (Swedish MK 1: sulphur $5 \mathrm{ppm}$ ) used in this study compared with the previously used older type of less purified fuel (Swedish MK 3: sulphur 900 ppm).

When interpreting the efficacy of the ceramic particle trap to prevent biological effects, it is recognised that the power of the study is dependent upon the number of subjects included. The number was based on earlier experiences of experimental air pollution studies in humans, and also the obvious need to limit the number of subjects for practical purposes as well as recruitment problems. Judging from the distributions of the measured variables, it seems that the ceramic trap did not tend to reduce biological effects to consider that the results might have been significant with more subjects. However, minor positive effects of the trap may have been overlooked.

The collection efficiency of a ceramic trap close to the engine has been reported to be $89 \%$ or more by weight during a laboratory running cycle. ${ }^{21} 22 \mathrm{We}$ found $46 \%$ reduction in particle number with an idling engine and the trap at the end of the tail pipe. The reduction in larger particles indicates that a substantial reduction of the total particle mass had probably occurred, but the studies are not fully comparable. The reason for the particle trap at the tail pipe not protecting significantly against the increases in $R_{a w}, S_{a w}$, and symptoms could be due to dynamic physical and chemical changes in the exhaust taking place in the tail pipe and ceramic trap; hot gases together with particles leave the engine, the temperature then decreases along the tail pipe, and gases with high boiling points are probably condensed on particles and also form new particles. Liquid particles and some of the condensed hydrocarbons could probably penetrate the ceramic trap and form new particles. This idea is supported by several earlier studies, ${ }^{21-24}$ and may explain why we obtained a relatively low collection efficiency of the particle number compared with mass collection of $89 \%$ or more obtained in earlier studies. ${ }^{21} 22$

Another possible reason why the ceramic partical trap was not highly efficient could be that components of the vapour phase, including highly irritant organic compounds such as acrolein and other aldehydes, were related to the acute effects. By contrast, irritant gaseous components such as $\mathrm{NO}_{2}$ probably had little effect as considerably higher concentrations are needed. ${ }^{25}$

It is concluded that diluted diesel exhaust caused increased symptoms of the eyes and nose, an unpleasant smell, and bronchoconstriction. The ceramic particle trap reduced the median particle number concentration by $46 \%$, which was not sufficient to protect significantly against the effects of exhaust found within the population studied.

We thank Kjell Englund, Annika Hagenbjsrk-Gustafsson, Torgny Lundberg, Anna Wenngren, and Per Hörstedt, Department of Pathology, University of Northern Sweden, Umeå, Henrik Landälv, Volvo, Gothenburg, and Lennart Schönning, OK, Stockholm, for technical assistance. This procet was Foundation, Sweden and Volvo Research Foundation and Volvo Foundation, Sweden and Volvo Rest Foundation, Sweden.

1 Reger R, Hancock J, Hankinson J, Hearl F, Merchant J. Coal miners exposed to diesel exhaust emissions. Ann Occup Hyg 1982;26:799-815.

2 Gamble J, Jones W, Minshall S. Epidemiological-environmental study of diesel bus garage workers: acute effects of $\mathrm{NO}_{2}$ and respirable particulate on respiratory system. Environ Res 1987;42:201-14.

3 Gamble J, Jones W, Minshall S. Epidemiological-environmental study of bus garage workers: chronic effects of diesel exhaust on the respiratory system. Environ Res 1987; 44:6-17.

4 Ayres SM, Evans R, Licht D, Griesbach J. Health effects of exposure to high concentrations of automotive emissions. Arch Environ Health 1973;27:168-78.

5 Ulfvarson U, Alexandesson R, Aringer L, Svensson E, Hedenstierna G, Hogstedt C, et al. Effects of exposure to vehicle exhaust on health. Scand $\mathcal{f}$ Work Environ Health 1987;13:505-12.

6 Ulfvarson U, Alexandersson R. Reduction in adverse effect on pulmonary function after exposure to filtered diesel exhaust. $A m \mathcal{F}$ Ind Med 1990;17:341-7.

7 Ulfvarson U, Alexandersson R, Dahlqvist M, Ekholm U, Bergström B. Pulmonary function in workers exposed to diesel exhausts: the effect of control measures. Am $\mathfrak{f}$ Ind Med 1991;19:283-9.

8 Attfield MD, Trabant GD, Wheeler RW. Exposure to diesel fumes and dust at six potash mines. Ann Occup Hyg 1982;26:817-31

9 Gamble J, Jones W, Hudak J. An epidemiological study of salt miners in diesel and nondiesel mines. $\mathrm{Am} \mathcal{F}$ Ind $\mathrm{Med}$ 1983;4:435-58.

10 Westerholm R. Inorganic and organic compounds in emissions from diesel powered vehicles: a review. National Swedish Environmental Protection Board 1987. (Report 3389.)

11 Levsen K. The analysis of diesel particulate: a review. Fresenius Zeitschrift für Analytische Chemie. 1988;331: 467-78.

12 Scheepers PTJ, Bos RP. Combustion of diesel fuel from a toxicological perspective; origin of incomplete combustion products: a review. Int Arch Occup Environ Health 1992 64:149-61.

13 Barbella R, Bertoli C, Ciajolo A, D'Anna A. Soot and unburnt hydrocarbon emissions from diesel engines. Combustions Science and Technology 1988;59:183-98.

14 Partridge PA, Shala FJ, Cernansky NP, Suffet IH. Comparison of diesel engine exhaust using chromatographic profiling techniques. Environmental Science and Technology profiling techniques

15 Schuetzle D, Frazier JA. Factors influencing the emission of vapor and particulate phase components from diese engines. In: Ishinishi $\mathrm{N}$, Koizumi A, McClellan RO, Stöber W, eds. Carcinogenic and mutagenic effects of diese engine exhaust. Amsterdam: Elsevier, 1986:41-63.

16 Ishinishi N, Koizumi A, McClelland RO, Stöber W Carcinogenic and mutagenic effects of deisel engine exhaust. Amsterdam: Elsevier, 1986.

17 Lewtas J. Evaluation of the mutagenicity and carcinogenicity of motor vehicle emissions in short-term bioassays. Environ Health Perspect 1983;47:141-52.

18 Rudell B, Sandström T, Hammarström U, Ledin M-C Hörstedt P, Stjernberg N. Evaluation of an exposure setup Hörstedt P, Stjernberg N. Evaluation of an exposure setup for studying effects of diesel exhaust

19 Levin J-O, Lindahl R, Andersson K. A passive sampler for formaldehyde in air using 2,4-dinitrophenylhydrazinecoated glass fiber filters. Environmental Science and Technology 1986;20:1273-6.

20 Borg GAV. Psychophysical bases of perceived exertion. Med Sci Sports Exerc 1982;14:377-81.

21 MacDonald JS. The effect of operating conditions on the effluent of a wall-flow monolith particulate trap. Society of Automotive Engineers 1983; 831711.

22 Baumgard KJ, Kittelson DB. The influence of a ceramic particulate trap on the size distribution of diesel particles. Society of Automotive Engineers 1985;850009:1-12.

23 Wiczynski PD, Johnson JH. The effect of a ceramic trap on diesel particulate fractions. Society of Automotive Engineers diesel particulate

24 Bagley ST, Gratz LD, Leddy DG, Johnson JH Characterization of particle- and vapor-phase organic fraction emissions from a heavy-duty diesel engine equipped with a particle trap and regeneration controls. Houghton, $\mathrm{MI}$ Department of Biological Sciences, Michigan Technica University, 1993:56. (Health Effects Institute research report)

25 Sandström T. Respiratory effects of air pollutants. Experimental studies in humans. Eur Respir $\mathcal{F} 1995 ; 8$ 976-95. 